\title{
Modal Realism, Still At Your Convenience
}

\author{
Harold Noonan
}

MARK JAGO Forthcoming in Analysis

Abstract: Divers (20I4) presents a set of de re modal truths which, he claims, are inconvenient for Lewisean modal realism. We argue that there is no inconvenience for Lewis.

Keywords: Modality, David Lewis, John Divers, possible worlds, spatiotemporal relations

\section{Introduction}

CCORDING To Divers (2OI4), there is a kind of de re modal truth that is
inconvenient for Lewisean modal realism. Such truths (he says) require
things in different worlds to be spatiotemporally related. But according to Lewisean modal realism, no things in different worlds are spatiotemporally related. So, if Divers is right about what these truths require, then Lewisean modal realism must be rejected.

The truths in question concern the spatiotemporal de re possibilities for some entity: that it could have been being bigger, or located elsewhere. The exact example requires some precision, as Divers acknowledges. We'll get to this in $\$ 2$.

We'll argue that a Lewisean modal realist needn't interpret such truths in the way Divers says she must. There's very natural ways for the Lewisian to read such truths, which don't require spatiotemporal relations between parts of different worlds. Indeed, Lewis (I986) made some brief remarks on the issue which support the very interpretation we favour here. Our envisioned Lewisean modal realist is the Lewis of On the Plurality of Worlds.

\section{Divers's Argument}

Possible worlds, according to Lewis, are to be understood as maximally spatiotemporally connected entities. Every part of a world bears spatiotemporal relations to every other part of that world, but to no part of any other world. That analysis provides a reductive understanding of possible world, and hence of possibility, in terms of an extensional, non-modal notion: spatiotemporal relatedness. This idea is a central tenet of Lewisean modal realism. Without it, the Lewisian has 
no reductive notion of modality to offer, and so loses her trump card over her non-Lewisian realist rivals.

Divers argues that the Lewisian is unsuccessful in this endeavour for, by her own lights, there must be spatiotemporal relations between things in distinct worlds. Spatiotemporal relations between distinct worlds are required, says Divers, to understand certain truths about how things could have been otherwise, spatiotemporally speaking. Divers's first-pass example is:

(I) Usain might have been taller than he actually is.

The Lewisian understands such truths, about how Usain might have been, in terms of some counterpart of Usain's. 'Usain might have been a cricketer' is interpreted as saying that some counterpart of Usain's is a cricketer. Similarly, the Lewisian should understand (I) as saying that some counterpart of Usain's is taller than Usain. That's a spatiotemporal comparison between that counterpart and Usain himself. If they are parts of different worlds, that comparison requires there to be spatiotemporal relations between entities in different worlds. And that is precisely what the Lewisian rules out.

This example won't do the work Divers wants of it, however. As he notes, the Lewisian doesn't require Usain's taller counterparts to belong to some other world. Usain could have been Joel Garner, three inches taller than Usain. That comparison requires only that two actual-world entities be spatiotemporally related. Divers needs an example which forces the counterpart in question to belong to some other world. After some discussion, he opts (for good measure) for these three examples (2014, 576):

(2) It is true of the tallest actual thing that it might have been taller (than it actually is).

(3) Whatever is the longest-lasting thing in the world, it might have lasted longer (than it actually does).

(4) The fastest ever thing might have been faster yet (than it actually is).

All assert de re modal truths of an actual entity. They are interpreted (by the Lewisian) as saying that some counterpart of that thing is taller (or longer-lasting, or faster) than it. Since the entity in question is the tallest (most long-lasting, fastest) of all in our world, any such counterpart must be part of some other world. So (says Divers) the spatiotemporal comparison (of height, longevity, or speed) is between entities in distinct possible worlds, contrary to what the Lewisian allows. That's why, according to Divers, these modal truths are inconvenient to the Lewisian. 


\section{No Inconvenience}

Divers's suggestion is one way to interpret each of $(2)-(4)$. For his argument to succeed, these must be the only plausible interpretations available. This is not so. Alternative readings of each are available. Here's one alternative reading of (2):

$\left(2_{d u p}\right)$ The tallest actual thing $t$ has a counterpart, $c$, in world $w$, which is taller than a duplicate of $t$ in $w$.

And here's another:

$\left(2_{c p}\right)$ The tallest actual thing $t$ has counterparts, $c_{1}$ and $c_{2}$, in world $w$, such that $c_{1}$ is taller than $c_{2}$.

If all internal duplicates of a thing are its counterparts, then $\left(2_{d u p}\right)$ implies $\left(2_{c p}\right)$.

Here's yet a third way to understand the claim. One might in general understand a 'taller-than' claim as making reference to an appropriate reference class (of people, or whatever). On that model, (I) is understood as the claim that Usain might have been taller in relation to members of his actual reference class. Call that reference class $R$. In counterpart terms, the claim amounts to this: Usain has a counterpart who is taller in relation to counterparts of the $R$ s than he (Usain) is in relation to the actual Rs. Similarly for (2) and the tallest actual thing. We'll focus on the first two interpretations, and won't discuss this third interpretation any further.

Are these plausible readings of (2)? They are, given Lewisian metaphysics. Here's why. To be plausible, any reading of (2) must be de re about whatever is the tallest actual thing - call it Bill. So what's at stake is whether it's plausible to say something about Bill by attributing a predicate to Bill's counterparts (or duplicates). But we already know the answer to this. We say of Humphrey that he might have won by attributing 'is the winner' to some counterpart of his. If $\left(2_{d u p}\right)$ or $\left(2_{c p}\right)$ failed to count as being about Bill, then 'Humphrey has a winning counterpart' would fail to be about Humphrey. No counterpart theorist will accept the Humphrey-objection, and so will say that both $\left(2_{d u p}\right)$ and $\left(2_{c p}\right)$ are genuinely about Bill. In that sense, they are plausible counterpart-theoretic readings of (2).

These suggested readings are, indeed, very close to what Lewis says on the matter:

Things that are parts of two worlds may be simultaneous or not, they may be in the same or different towns, they may be near or far from one another, in very natural counterpart-theoretic senses. But these are not genuine spatiotemporal relations across worlds. The only trans-world relations involved are internal relations of similarity; not indeed between the very individuals that are quasi-simultaneous (or whatever), but between larger duplicate parts of the two worlds wherein those individuals are situated. (Lewis I986, 7I) 
Here, Lewis suggests both a 'counterpart' and a 'duplicate' reading of 'quasispatiotemporal' relations. There is a sense of 'we might have lived fifty miles further north than we actually do' for the truth of which it suffices that there are, in another world, counterparts of us living fifty miles north of a town which is a duplicate, or otherwise a good counterpart, of that in which we actually live.

These suggested readings are available, and are plausible. How do we then infer that they are the correct readings (and that Divers's is not)? We do so via what Lewis calls 'the cardinal principle of semantics', namely to 'interpret the message to make it make sense - to make it consistent, and sensible to say' (Lewis I996, 566). Given Lewisian metaphysics, there are no spatiotemporal relations between things in distinct worlds. So, to interpret a speaker who makes a spatiotemporal comparison as saying something 'consistent and sensible', we should interpret her (as far as is reasonable) as speaking about things in the same world. Where one interpretation of a spatiotemporal comparison involves worldmates and another does not, charity urges us towards the former. So charity urges us towards interpreting $(2)$ as $\left(2_{d u p}\right)$ or $\left(2_{c p}\right)$, and away from Divers's interpretation.

\section{Actually?}

One may object that we are ignoring the semantic effect of 'actually' in (2). 'Actually' restricts (or shifts) the domain of quantification to the actual world. And so, one may argue, 'taller than he actually is' requires a comparison to an actual entity: something part of our world. If that is so, then Divers's argument regains its bite. But it is not so. As any competent speaker of English knows, 'might have been taller than he actually is' means just 'might have been taller (than he is)'. 'Actually' adds nothing to what is conveyed. So it would be bizarre if 'might have been taller than he actually is' contained a mandatory semantic restriction not found in 'might have been taller (than he is)'.

What both phrases require for their truth is a comparison, height-wise, between how Bill (the tallest entity) might have been and how Bill is. But how to capture how Bill is is up for theoretical grabs. And, according to the orthodox Lewisian doctrine, a world represents how Bill is, height-wise, via an intrinsic duplicate of Bill's at that world. By the same token, a world represents how Bill actually is, height-wise, via an intrinsic duplicate of Bill's at that world. There's no difference here, since representing how Bill actually is amounts to no more and no less than representing how Bill is.

(The Lewisian orthodoxy thus supports the $\left(2_{d u p}\right)$ reading of (2). A less orthodox Lewisian might allow how Bill is to be represented via a non-duplicate counterpart of Bill's. That approach would, in addition, support the $\left(2_{c p}\right)$ reading of (2).)

A Lewisian counterpart theory is not a translation manual, from English (or 
modal logic) to the extensional language of counterparts. (Perhaps Lewis I968 can be read that way, in making the point that counterpart theory is at least as expressive as QML. But Lewis is clear that this is not how to read Lewis I986.) As Lewis says, we must always 'interpret the message to make it make sense'. And to do so, in our examples, one must interpret via a duplicate (or otherwise a good counterpart) at the world in question.

The Lewisian is thus not inconvenienced by height-wise (or other spatiotemporal) comparisons. Following Lewis, she understands such talk (when it invokes mere possibilia) in a 'very natural counterpart-theoretic sense', via a duplicate of the thing in question. Spatiotemporal comparisons are thus always between worldmates, just as the Lewisian metaphysical definition of a world requires.

\section{References}

Divers, J. (20I4). An inconvenient modal truth, Analysis 74(4): 575-577.

URL: http://analysis.oxfordjournals.org/content/74/4/575.abstract

Lewis, D. (I968). Counterpart theory and quantified modal logic, The Journal of Philosophy 65(5): II3-I 26.

Lewis, D. (1986). On the Plurality of Worlds, Blackwell, Oxford.

Lewis, D. (I996). Elusive knowledge, Australasian Journal of Philosophy 74(4): 549-567. 